\title{
Effects of the molecular weight of hyaluronic acid and its action mechanisms on experimental joint pain in rats
}

Sachiko Gotoh, Jun-Ichi Onaya, Mayumi Abe, Kyosuke Miyazaki, Akio Hamai, Katsuyuki Horie, Kiyochika Tokuyasu

\begin{abstract}
Objectives-It has been shown previously that hyaluronic acid (HA) has an analgesic action on bradykinin induced pain in the knee joints of rats. This study further clarifies the effects of the molecular weight of $\mathrm{HA}$ and its mechanism of action in the same model using $\mathrm{HA}$ of molecular weight 800 to $2.3 \times 10^{6}$ daltons and a bradykinin antagonist.

Methods-Bradykinin and the test HA preparations were given to rats by intraarticular injection, and the severity of pain was evaluated by a change in the walking behaviour.

Results-HA with a molecular weight greater than 40 kilodaltons produces analgesic effects with a simultaneous or earlier injection. The $\mathrm{ID}_{50}$ values of $\mathrm{HA}$ with molecular weight $40,310,860$, and 2300 kilodaltons were greater than $2 \cdot 5,0 \cdot 6$, 0.07 , and $0.06 \mathrm{mg} / \mathrm{joint}$ respectively. The duration of the analgesic effect of 860 and 2300 kilodalton HA was 72 hours at $10 \mathrm{mg} / \mathrm{ml}$, whereas that of 310 kilodalton HA was short, being undetectable after 24 hours. The analgesic action of HA of 860 kilodaltons was not changed by pretreatment with four saccharide $\mathrm{HA}$ and inhibited by pretreatment with HA larger than six to eight saccharides, capable of binding to HA receptors. Further, HA did not interfere with the analgesic action of the bradykinin antagonist, indicating that HA does not directly bind with bradykinin receptors.

Conclusions-HA with a molecular weight of greater than 40 kilodaltons produced an analgesic effect, and $H A$ of 860 and 2300 kilodaltons produced high and longlasting analgesia. These effects of HA appear to be caused by the interaction between HA and HA receptors.
\end{abstract}

(Ann Rheum Dis 1993; 52: 817-822)

The main clinical symptom of osteoarthritis is joint pain, which makes daily life unpleasant. The pain may also promote progress of the disease process, ${ }^{1-3}$ and result in decreased mobility of the joint due to lack of use. Consequently, reducing pain is important for the maintenance of joint activity and quality of life.
Hyaluronic acid (HA) is the main component of synovial fluid. High molecular weight HA with a random coil configuration has viscoelasticity and occupies a large amount of hydrodynamic space in solution. ${ }^{4}$ Its functions in the joint are considered to be as a lubricant, ${ }^{56}$ a protector of cartilage,${ }^{7-9}$ and an effector of the metabolism of synovial tissue. ${ }^{10}$

Intra-articular HA treatment of the knee of patients with osteoarthritis reduces painful symptoms and improves general activities of daily living and joint mobility. ${ }^{11-13}$ The mechanism of joint pain is not clear, so the role of HA in pain suppression requires further study. In our previous study using the bradykinin induced joint pain model in rats, we showed that HA acting in a joint can induce analgesia. ${ }^{14}$

In this study we investigated the effects of the molecular weight of HA on analgesia and further attempted to clarify its mode of action using HA of molecular weight 800 to $2.3 \times 10^{6}$ daltons in the same model.

\section{Materials and methods}

MATERIALS

HA preparations were extracted and highly purified from rooster combs; their average molecular weights were 6.8 (HA 6.8), 40 (HA 40), 310 (HA 310), 860 (HA 860), and 2300 kilodaltons (HA 2300). The molecular weight was calculated from the intrinsic viscosity according to the formula of Laurent et al ${ }^{15} \mathrm{HA}$ of four saccharide units (4S HA) and a mixture of six and eight saccharide HA (8S HA) were prepared from HA 6.8 as follows. HA 6.8 was digested by partially purified bovine testicular hyaluronidase (Seikagaku, Tokyo, Japan) at $50^{\circ} \mathrm{C}$ for 96 hours. After digestion, degraded HA was fractionated by ethanol precipitation, followed by gel filtration chromatography with Cellulofine-GCL $90 \mathrm{~m}$ (Seikagaku). Each oligosaccharide fraction was desalted, lyophilised and analysed by high performance liquid chromatography (Hitachi Model 638-30) according to the method of Yoshida et al. ${ }^{16}$ Bradykinin and bradykinin specific inhibitor (bradykinin antagonist), Des-Arg ${ }^{9}-\left(\mathrm{Leu}^{8}\right)$ bradykinin, were purchased from the Peptide Institute (Osaka, Japan). All preparations were dissolved in phosphate buffered saline ( $\mathrm{pH} \mathrm{7 \cdot 4)}$ or saline. 
Table 1 Changes in walking behaviour caused by intra-articular injection of bradykinin

\begin{tabular}{|c|c|c|}
\hline Walking behaviour & Grade & Indication \\
\hline Normal & & No change in walking \\
\hline Lameness & $\begin{array}{l}\text { Lam-I } \\
\text { Lam-II }\end{array}$ & $\begin{array}{l}\text { Lameness alone for } 20 \text { seconds or less } \\
\text { Lameness alone for more than } 20 \text { seconds }\end{array}$ \\
\hline Pulling & $\begin{array}{l}\text { Pul-I } \\
\text { Pul-II }\end{array}$ & $\begin{array}{l}\text { Only transient pulling up of the injected leg (five seconds or less) } \\
\text { Pulling up of the injected leg, followed by lameness }\end{array}$ \\
\hline Three legs & $\begin{array}{l}\text { Thr-I } \\
\text { Thr-II }\end{array}$ & $\begin{array}{l}\text { Transient (for five seconds or less) walking on three legs, followed by lameness } \\
\text { Walking on three legs for more than five seconds, followed by lameness }\end{array}$ \\
\hline
\end{tabular}

INDUCTION OF KNEE PAIN AND EVALUATION SYSTEM

Male SD rats, bred by Japan SLC (Shizuoka, Japan), aged 5-6 weeks, were used. The animals were previously placed for more than five minutes in long steel cages, allowing clear observation of their feet, and acclimatised to the new environment. Each injection was carried out with $0.05 \mathrm{ml} /$ joint a time. A control group was set up in every experiment to check the reproducibility. Tests were performed by three workers; one operator prepared and injected the test solutions and the rest of the workers observed the animals for two minutes and evaluated the pain reaction blindly. Intraarticularly injected bradykinin causes short knee pain reactions from five to 10 seconds to about two minutes after the injection. A low dose of bradykinin causes transient lameness, which is extended by slightly increasing the amount of bradykinin. If the dose is increased further, pain symptoms include pulling up of the injected leg, and subsequently walking on the three uninjected legs. The last two were followed by lameness in most instances. The changes were differentiated and evaluated as shown in tables 1 and 2 .

STATISTICS

Results are shown as the mean (SE) of several experiments. Differences among the groups were evaluated by one way analysis of variance followed by Newman-Keuls's test for multiple comparisons.

\section{Results}

BRADYKININ INDUCED KNEE JOINT PAIN

RESPONSE AND ITS REPRODUCIBILITY

Bradykinin caused dose dependent pain reactions in rats when $0.05 \mathrm{ml}$ was injected at a concentration of $0.56-45 \mu \mathrm{g} / \mathrm{ml}$ (fig 1 ). The analgesic score was 3 at a bradykinin concentration of $5 \mu \mathrm{g} / \mathrm{ml}$. A score of 3 means that the rats pulled up the injected leg, followed by lameness, and the rating of score 3 is easy. Unless noted otherwise, $5 \mu \mathrm{g} / \mathrm{ml}$ bradykinin was used to induce pain in the subsequent

Table 2 Behaviour grading criteria for evaluating pain reaction

\begin{tabular}{lll}
\hline $\begin{array}{l}\text { Grade of } \\
\text { algesia }\end{array}$ & $\begin{array}{l}\text { Walking } \\
\text { behaviour }\end{array}$ & $\begin{array}{l}\text { Evaluation } \\
\text { score }\end{array}$ \\
\hline None & Normal walking & 0 \\
Slight & Lam-I & 1 \\
Mild & Lam-II or Pul-I & 2 \\
Moderate & Pul-II or Thr-I & 3 \\
Severe & Thr-II & 4 \\
\hline
\end{tabular}

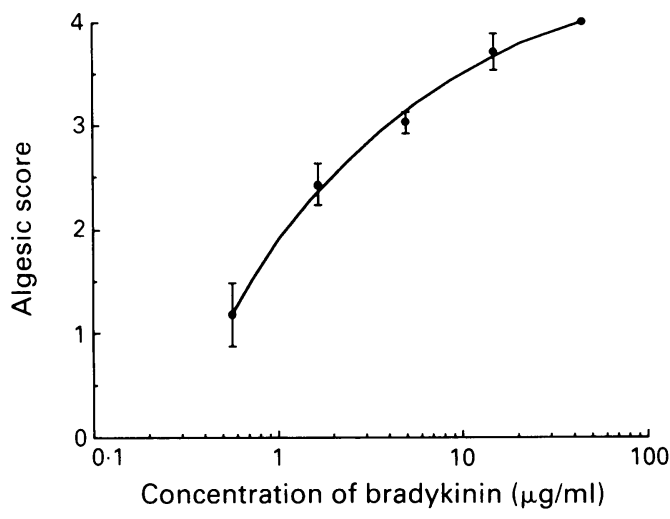

Figure 1 Dose-response curve of pain response induced by intra-articular injection of bradykinin $0.05 \mathrm{ml}$ in rats. Results are shown as mean (SE) values $(n=6-38)$.

examinations. There was no difference in the pain level among experimental days when $5 \mu \mathrm{g} / \mathrm{ml}$ bradykinin or bradykinin 30 minutes after a saline injection was given (fig 2).

EFFECTS OF MOLECULAR WEIGHT OF HA INJECTED WITH BRADYKININ ON PAIN RESPONSE HA preparations of different molecular weights of various concentrations were injected with bradykinin simultaneously. HA 40, 310, 860, and 2300 inhibited the pain at concentrations of $\geqslant 50, \geqslant 10$, $\geqslant 2.5$, and $\geqslant 1.25 \mathrm{mg} / \mathrm{ml}$ respectively. HA $6 \cdot 8$ had no effect, even at $100 \mathrm{mg} / \mathrm{ml}$ (fig 3).

The percentage inhibition was obtained with respect to the control. The $\mathrm{ID}_{50}$ values of $\mathrm{HA}$ $40,310,860$, and 2300 were $>50,12,1 \cdot 4$, and $1.2 \mathrm{mg} / \mathrm{ml}$ as concentration, and $>2.5,0.6$, 0.07 , and $0.06 \mathrm{mg} /$ joint as dose respectively (fig 4). The $\mathrm{ID}_{50}$ value decreased with increased molecular weight of HA, but no difference between the ID $_{50}$ values of HA 860 and HA 2300 was noted.

DURATION OF ANALGESIA

A pain reaction was induced $24,48,72$, and 96 hours after administration of HA 310,860 , and 2300. HA 860 and 2300 inhibited pain at $\geqslant 5 \mathrm{mg} / \mathrm{ml}$ after 24 hours, at $10 \mathrm{mg} / \mathrm{ml}$ after 48 and 72 hours, and had no effect after 96 hours. HA 310 had no effect at any of these times (fig 5).

EFFECTS OF HA OLIGOSACCHARIDE ON ANALGESIA OF HA 860

This test was conducted to examine whether the analgesic action of HA is produced by the interaction of HA with HA receptors. It is well 


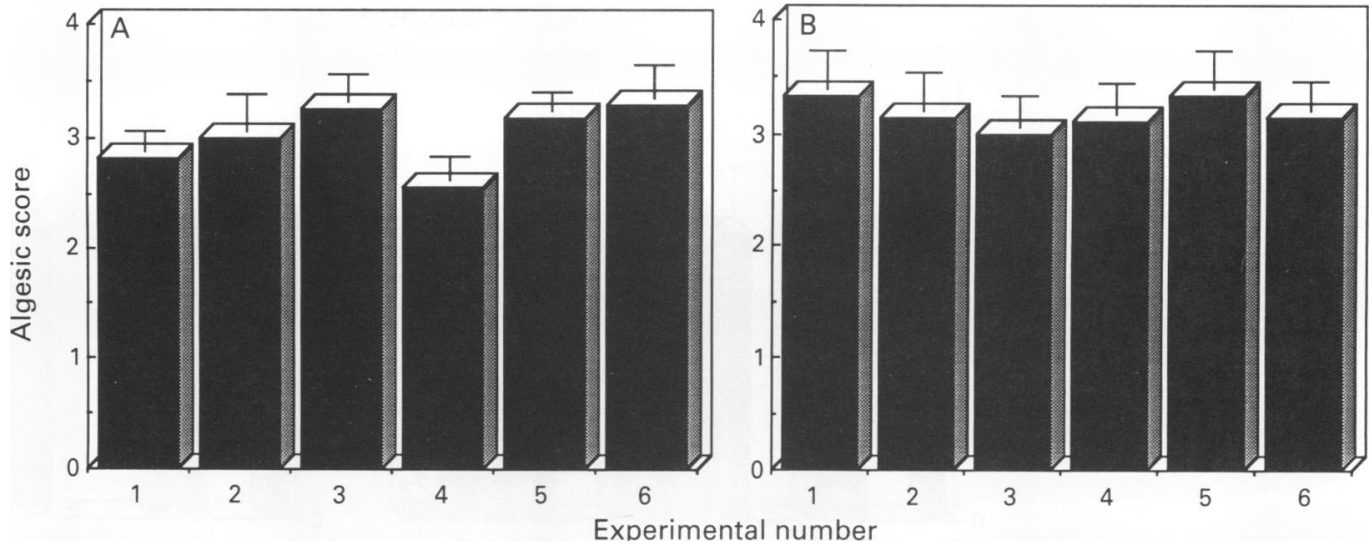

Figure 2 Reproducibility of bradykinin induced knee pain response. (A) Bradykinin injection of $5 \mu \mathrm{g} / \mathrm{ml}(n=4-8)$ (B) Bradykinin of $5 \mu \mathrm{g} / \mathrm{ml}$ at 30 minutes after saline injection $(n=3-10)$.

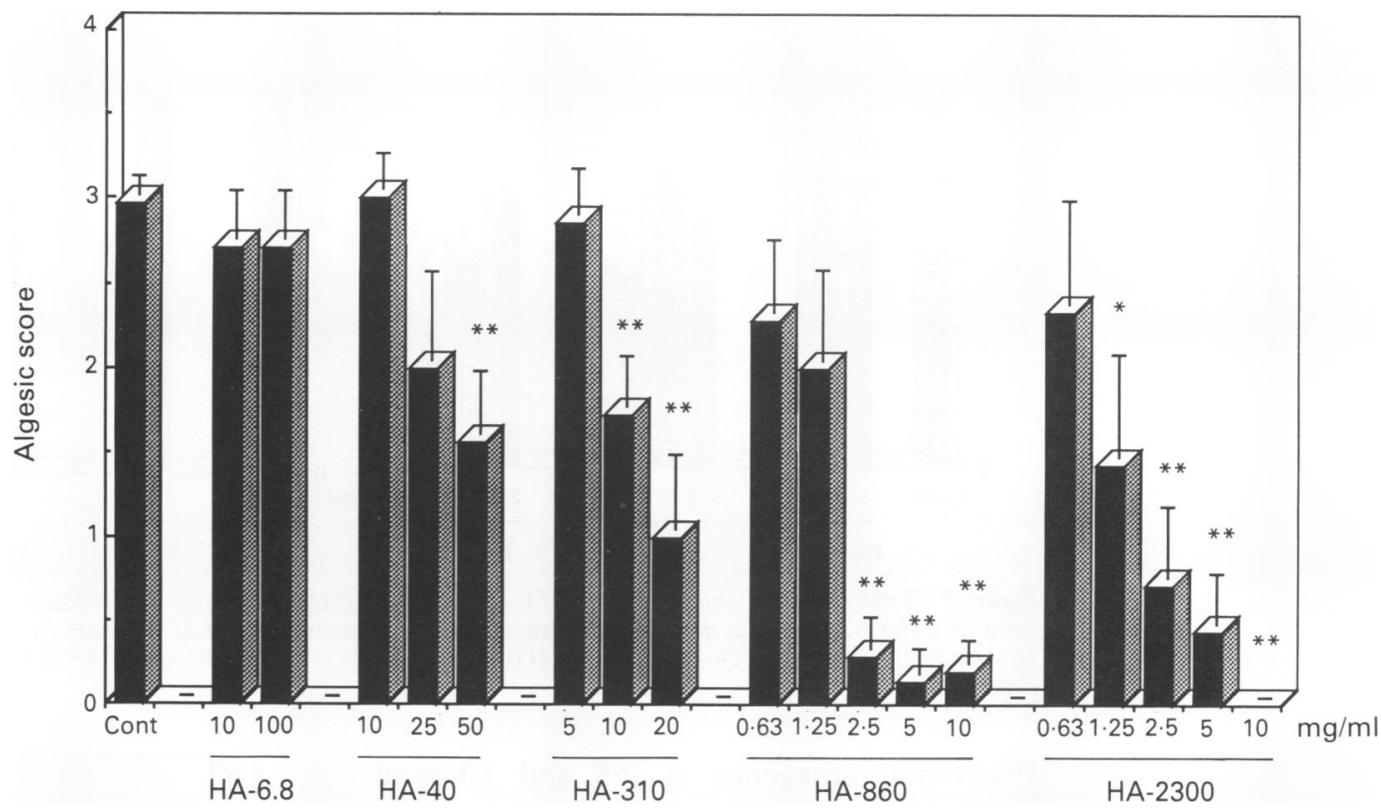

Figure 3 Effects of hyaluronic acid (HA) with different molecular weights on bradykinin induced joint pain in rats. Each $H A$ was injected into a joint simultaneously with bradykinin $(n=6-31) .{ }^{*} p<0 \cdot 05 ;{ }^{\star *} p<0 \cdot 01$. Molecular weight of $H A-6 \cdot 8, H A-40, H A-310, H A-860$, and $H A-2300$ are $6 \cdot 8,40,310,860$, and 2300 kilodaltons.

known that four saccharide HA does not bind to the HA receptors on the cell surface, and HA with six or eight saccharide units is the minimum size for binding. ${ }^{17} 18$ Thus we examined whether the analgesic effect of HA 860 was suppressed by pretreatment with

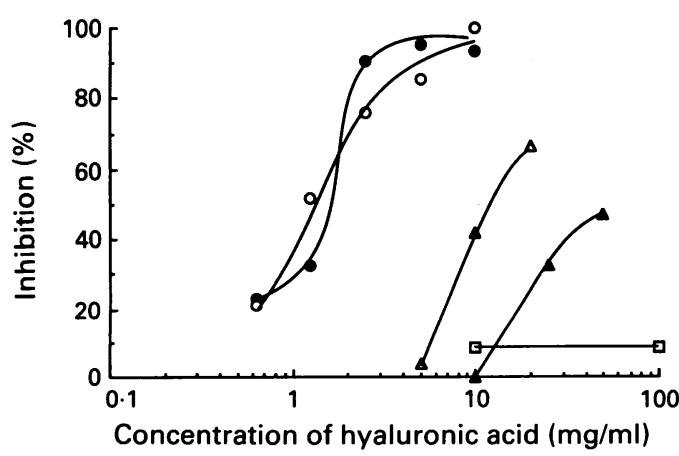

Figure 4 Dose-response curves of hyaluronic acid $(H A)$ with different molecular weights. Each percentage inhibition of pain response was obtained with respect to the control using the data of fig 3. ( $\square$ ) $H A-6 \cdot 8$; (4) $H A-40$; $\triangle H A-310$; (O) $H A-860$; and (O) $H A-2300$. The abbreviations are the same as those in
4S HA, 8S HA, and HA 6.8. The pain reaction was induced by the injection of bradykinin alone and by the simultaneous injection of bradykinin and $\mathrm{HA} 860$ of $10 \mathrm{mg} / \mathrm{ml} 30$ minutes after administration of $4 \mathrm{~S} \mathrm{HA}, 8 \mathrm{~S} \mathrm{HA}$, and HA 6.8. HA 860 inhibited the pain in knees with preinjected saline, $4 \mathrm{~S} \mathrm{HA}$ of $10 \mathrm{mg} / \mathrm{ml}$, and $8 \mathrm{~S} \mathrm{HA}$ of $2.5 \mathrm{mg} / \mathrm{ml}$, but did not inhibit it in knees injected with $10 \mathrm{mg} / \mathrm{ml}$ $8 \mathrm{~S} \mathrm{HA}$ or $\geqslant 2.5 \mathrm{mg} / \mathrm{ml}$ HA 6.8 . The results indicated that pretreatment with $8 \mathrm{~S} \mathrm{HA}$ and HA 6.8 suppressed the analgesic effect of HA 860, and HA 6.8 greatly decreased it, whereas 4 S HA did not (fig 6). These findings suggest that the analgesia of $\mathrm{HA}$ is produced by the interaction between $\mathrm{HA}$ and HA receptors.

EFFECT OF LOW MOLECULAR WEIGHT HA ON ANALGESIA OF BRADYKININ ANTAGONIST To examine whether HA binds directly to bradykinin receptors and competes against bradykinin antagonist activity, a test was conducted with the combined use of HA. 

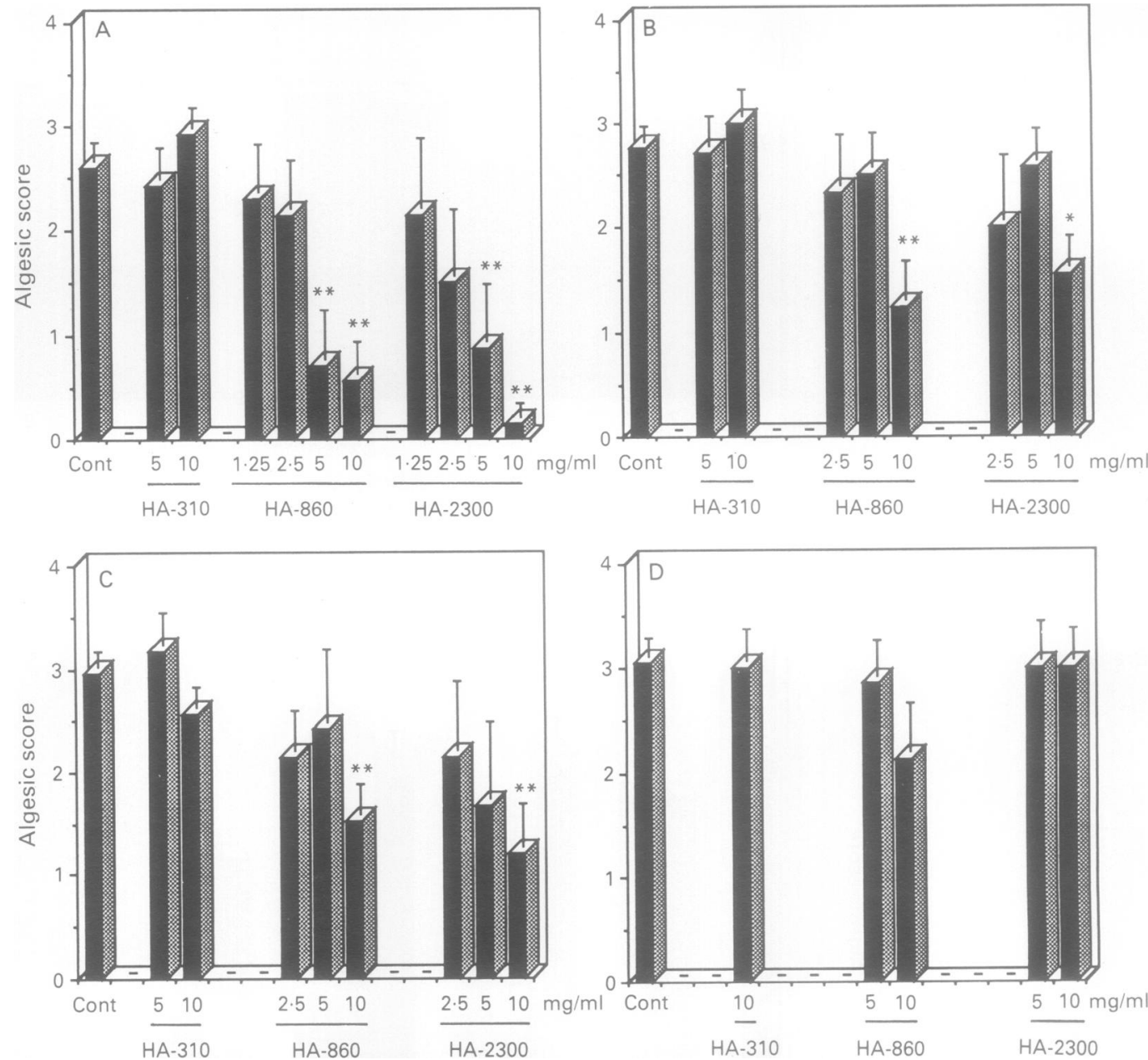

Figure 5 Time courses of analgesic effects of hyaluronic acid $(H A)$ with different molecular weights. $H A$ was administered intra-articularly 24, 48, 72, and 96 hours before the bradykinin injection. $(A) 24$ hours $(n=6-28) ;(B) 48$ hours $(n=6-21)$; $(C) 72$ hours $(n=6-27)$; and $(D) 96$ hours $(n=7-19)$. ${ }^{*} p<0.05 ;{ }^{*} p<0 \cdot 01$. The abbreviations are the same as those in fig 3.

Bradykinin antagonist at 2.5 and $10 \mu \mathrm{g} / \mathrm{ml}$ inhibited pain, depending on the dose, when injected simultaneously with $5 \mu \mathrm{g} / \mathrm{ml}$ bradykinin (fig 7). As the bradykinin antagonist has a short life in vivo, bradykinin was injected five minutes after administration of the bradykinin

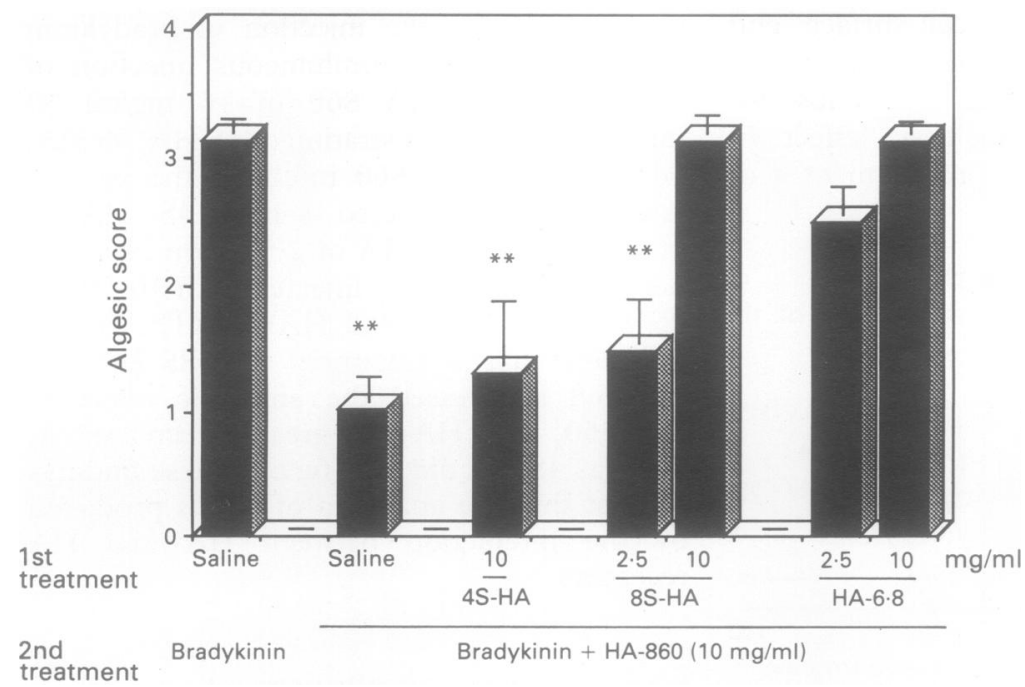

Figure 6 Antagonistic effects of hyaluronic acid $(H A)$ oligosaccharide on analgesia of $H A$ with high molecular weight. Saline and each oligosaccharide were administered intra-articularly 30 minutes before bradykinin or injection of a combination of bradykinin and high molecular weight $H A(n=6-36)$. ${ }^{\star *} p<0 \cdot 01$. (4S-HA) four saccharide $H A$, (8S-HA) mixture of six and eight saccharide $H A$. The abbreviations are the same as those in fig 3.

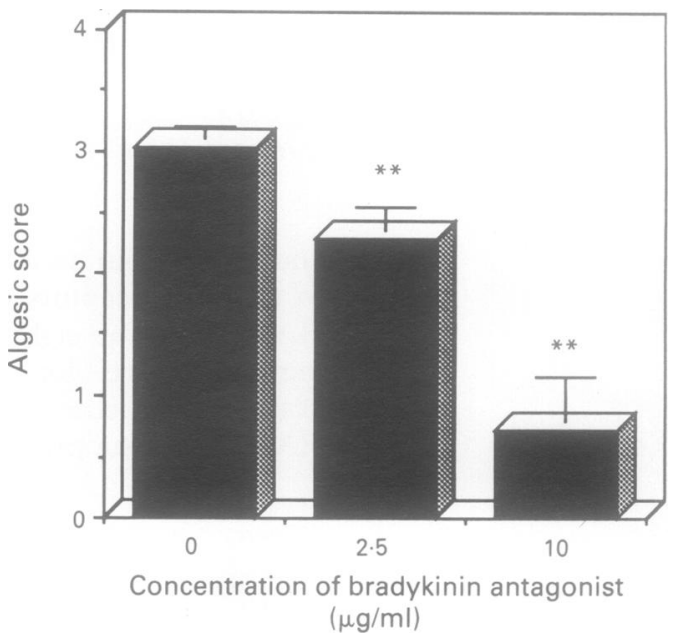

Figure 7. Antagonistic effect of Des- $\mathrm{Arg}^{9}-\left(\mathrm{Leu}^{8}\right)$-bradykinin (bradykinin antagonist) on bradykinin induced pain response. Drug was injected simultaneously with bradykinin $(n=7-38)$. ${ }^{\star *} p<0 \cdot 01$. Concentration of bradykinin, $5 \mu \mathrm{g} / \mathrm{ml}$.

antagonist. This short interval between injections enhanced the pain. Thus in this test a bradykinin concentration of $2.5 \mu \mathrm{g} / \mathrm{ml}$ was chosen to obtain an analgesic score of 3 in the control group for easy rating. HA $6 \cdot 8$ was selected as it binds to HA receptors but shows no analgesia, and will suppress bradykinin antagonist activity if it binds to bradykinin 


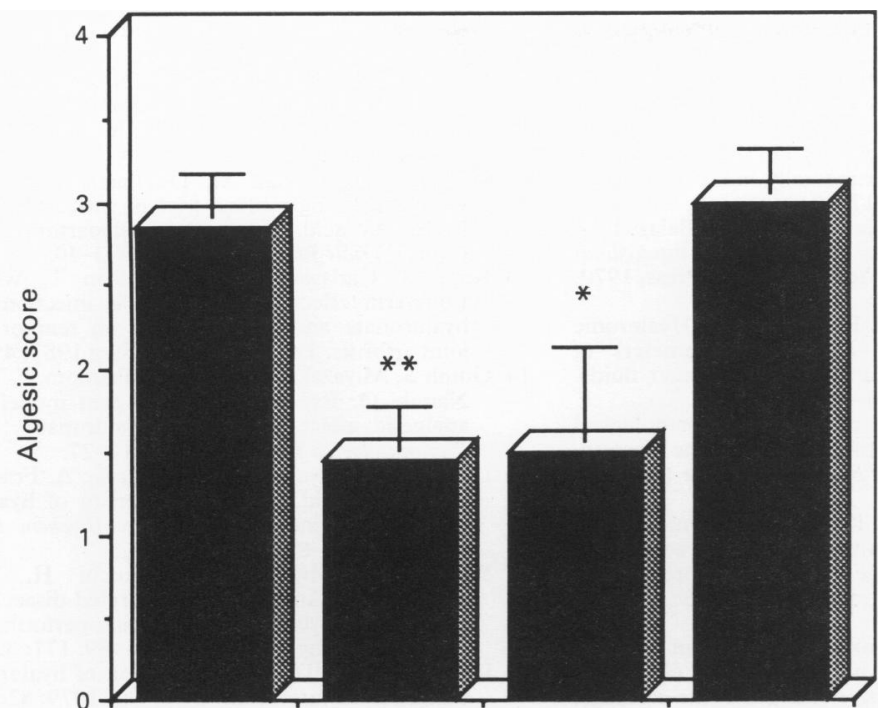

1st treatment

Bradykinin antagonist

$\mathrm{HA}-6 \cdot 8$

2nd treatment

Bradykinin

Figure 8 Effect of low molecular weight hyaluronic acid $(H A)$ on analgesic effect of bradykinin antagonist. Drugs were given intra-articularly five minutes before bradykinin injection $(n=7-38)$. ${ }^{*} p<0.05 ;{ }^{*} p<0.01$. Concentrations of bradykinin, bradykinin antagonist and low molecular weight $H A(H A-6 \cdot 8)$ were $2 \cdot 5,10$, and $10 \mathrm{mg} / \mathrm{ml}$ respectively. The abbreviations are the same as those in figs 3 and 7 .

receptors. A pain reaction was induced by injecting $2.5 \mu \mathrm{g} / \mathrm{ml}$ bradykinin five minutes after administration of bradykinin antagonist $(10 \mu \mathrm{g} / \mathrm{ml})$, HA $6.8(10 \mathrm{mg} / \mathrm{ml})$, and a mixture of the two. Bradykinin antagonist and the mixture with HA 6.8 inhibited the pain equally, but HA 6.8 did not. This indicates that HA had no effect on the interaction between bradykinin and bradykinin receptors (fig 8).

\section{Discussion}

Although many investigations have suggested that HA plays an important part in various biological activities, the precise function of $\mathrm{HA}$ in these events is not yet clear. Nevertheless, it is likely that the influence of HA depends on (a) its remarkable hydrodynamic properties and $(b)$ its interaction with the cell surface. ${ }^{19}$

We hypothesised that information on the effects of the molecular weight of HA might be the key for revealing the mechanisms of the analgesia of HA. In this study using HA with a molecular weight of 800 to $2.3 \times 10^{6}$ daltons, the results indicated that $\mathrm{HA}$ with a molecular weight range of 40 to 860 kilodaltons produced an analgesic action dependent on molecular weight and concentration. HA 860 and HA 2300 showed almost the same ID $_{50}$ value at 1.4 and $1.2 \mathrm{mg} / \mathrm{ml}(0.07$ and $0.06 \mathrm{mg} /$ joint $)$ on simultaneous injection with bradykinin, and the same duration of analgesia (72 hours). HA 310 showed a short term effect, suggesting that a relatively high molecular weight $\mathrm{HA}$ is needed to produce longlasting analgesia. HA 860 and HA 2300 show almost the same activity, however, in spite of the fact that HA 2300 has a higher viscosity. A previous study suggested that the analgesic effect of HA was obtained by covering the tissue and cell surface pain receptors, and not by viscosity. ${ }^{14}$ From these findings, we have concluded that the analgesic effect of HA is due to its affinity to cells rather than to the direct hydrodynamic physical properties and viscosity corresponding to molecular weight.

The interaction of HA with HA binding receptors on the cell surface is considered to be an important factor in determining cell behaviour. Underhill and Toole ${ }^{17}$ and Laurent et $a l^{18}$ investigated the effect of the molecular weight of HA on the binding ability to the receptor in cultured cells in vitro and found that binding of HA to its receptors occurred when the saccharide number of HA was larger than six or eight. The larger the molecule of $\mathrm{HA}$, the higher the affinity; when the hydrodynamic size of exogenous HA was very large, the number of binding molecules that could occupy the available cell surface receptors was reduced.

This led us to investigate the role of HA receptors on the cell surface in the analgesic action of HA. Among 4S HA, 8S HA, and HA $6 \cdot 8,8 \mathrm{~S} \mathrm{HA}$ and HA $6 \cdot 8$, capable of binding to receptors, suppressed the biological activity of HA 860, and the degree of inhibition depended on the concentration and saccharide chain length of HA. On the other hand, the action of the bradykinin antagonist was not affected by $\mathrm{HA} 6 \cdot 8$, indicating that $\mathrm{HA}$ molecules do not appear to bind directly to bradykinin receptors. Consequently, the effect of HA appears to be brought on by the interaction between HA and HA receptors, and not by the interaction between HA and bradykinin receptors.

We had previously proposed another possible explanation for the analgesic action. HA has an expanded random coil configuration which causes entanglement between neighbouring molecules. We had thought that $\mathrm{HA}$ in the synovial fluid may trap bradykinin in its molecule by the ion bonds formed between the carboxyl base in HA with the negative charge and bradykinin with the cation charge, followed by maintaining an entangled coil configuration. This is not feasible, however, because analgesia by HA 860 no longer occurred after HA oligosaccharide pretreatment, as shown in fig 5 , and when the bradykinin solution was dialysed with the filter membrane, the dialysis rate of bradykinin was not changed by adding $\mathrm{HA}$ in solution (data not shown).

The results of this study indicate that (a) HA with a molecular weight greater than 40 kilodaltons produces analgesic effect, $(b)$ high and longlasting analgesia is induced by $\mathrm{HA}$ with molecular weights of 860 and 2300 kilodaltons equally, and $(c)$ that analgesia was inhibited by oligosaccharides of HA. Moreover, HA did not directly bind to bradykinin receptors, indicating that analgesia of HA appears to be brought on by the interaction of $\mathrm{HA}$ and $\mathrm{HA}$ receptors on or surrounding the free nerve endings that detect pain in the joint tissue. 
1 Pernow B. Role of tachykinins in neurogenic inflammation. f Immunol 1985; 135: 812s-5s.

2 Lam F Y, Ferrell W R. Inhibition of carrageenan induced inflammation in the rat knee joint by substance $P$ antagonist. Ann Rheum Dis 1989; 48: 928-32.

3 Dardick S J, Basbaum A I, Levine J D. The contribution of pain to disability in experimentally induced arthritis. Arthritis Rheum 1986; 29: 1017-22.

4 Laurent T C. Structure of hyaluronic acid. In: Balazs E A, ed. Chemistry and molecular biology of the intercellular matrix. Vol. 2. London, New York: Academic Press, 1970: 703-32.

5 Balazs E A, Watson D, Duff I F, Roseman S. Hyaluronic acid in synovial fluid. I. Molecular parameters of hyaluronic acid in normal and arthritic human fluids. hyaluronic acid in normal and

6 Kondo H. A study on viscosity of normal and pathological human synovial fluid. Affecting factors on the viscosity and its effect on lubrication. Kitasato Medicine 1980; 10: 485-98

7 Sakamoto T, Mizuno S, Maki T, Suzuki K, Yamaguchi T, Iwata $\mathrm{H}$. Studies on the affinity of hyaluronic acid to the surface of articular cartilage and the suppression of proteoglycan releases from matrix. Orthopedic Research Science 1984; 11: 264-6.

8 Toyoshima $\mathrm{H}$. The influence of synovectomy on articular cartilage of rabbit knee and preventive effects of hyaluronic acid on degenerative changes of the cartilage. fournal of the Tokyo Women's Medical College 1978; 48: fournal of

9 Sommarin Y, Heinegård D. Specific interaction between cartilage proteoglycans and hyaluronic acid at the chondrocyte cell surface. Biochem f 1983; 214: 777-84.

10 Smith M M, Ghosh P. The synthesis of hyaluronic acid by human synovial fibroblasts is influenced by the nature of the hyaluronate in the extracellular environment. Rheumatol Int 1987; 7: 113-22.

11 Shichikawa K, Maeda A, Ogawa N. Clinical studies of the intraarticular injection of sodium hyaluronate in the treatment of osteoarthritis of human knee. Ryumach 1983; 23: 280-90.

12 Bragantini A, Cassini M, De Bastiani G, Perbellini A Controlled single blind trial of intraarticularly injected hyaluronic acid (Hyalgan) in osteoarthritis of the knee. Clinical Trials fournal 1987; 24: 333-40.

13 Kopp S, Carlsson G E, Haraldson T, Wenneberg B. Longterm effect of intraarticular injections of sodium hyaluronate and corticosteroid on temporomandibular joint arthritis. F Oral Maxillofac Surg 1987; 45: 929-35.

14 Gotoh S, Miyazaki K, Onaya J, Sakamoto T, Tokuyasu K, Namiki O. Experimental knee pain model in rats and Namiki O. Experimental knee pain model in rats and analgesic effect of sodium hyaluron

15 Laurent T C, Ryan M, Pietruszkiewic A. Fractionation of hyaluronic acid. The polydispersity of hyaluronic acid from the bovine vitreous body. Biochem Biophys Acta $1960 ; 42: 476-85$

16 Yoshida K, Miyauchi S, Kikuchi H, Tawada A Tokuyasu K. Analysis of unsaturated disaccharides from glycosaminoglycuronan by high-performance liquid chromatography. Anal Biochem 1989; 177: 327-32.

17 Underhill C B, Toole B P. Binding of hyaluronate to the surface of cultured cells. $\mathcal{F}$ Cell Biol 1979; 82: 475-84.

18 Laurent T C, Fraser R E, Pertoft H, Smedsrød B. Binding of hyaluronate and chondroitin sulphate to liver of hyaluronate and chondroitin sulphate

19 Toole B P, Goldberg R L, Chi-Rosso G, Underhill C B, Orkin R W. Hyaluronate-cell interaction. In: Trelstadt R L, ed. The role of extracellular matrix in development. New York: Liss, 1984: 43-66. 